\title{
Serving the old: ageing and economic growth
}

\author{
By Bas van Groezen^, Lex Meijdam†, and Harrie A. A. Verbon $\dagger$
}

${ }^{*}$ Utrecht School of Economics, Utrecht University, Vredenburg 138, 3511 BG

Utrecht, The Netherlands; e-mail: B.vanGroezen@econ.uu.nl

$\dagger$ Department of Economics and CentER for Economic Research, Tilburg University, The Netherlands.

\begin{abstract}
This paper focuses on the effect that population ageing has on the production structure of the economy and consequently on economic growth. We consider an economy that consists of a service sector and a commodity sector. Productivity growth only occurs in the latter sector and is assumed to depend positively on its size. We show that if old agents mainly demand labour-intensive services, the effect of increasing longevity on growth depends on the substitutability of labour and capital in a closed economy. However, ageing unambiguously decreases long-run growth in a small open economy.
\end{abstract}

JEL classification: D91, E60, H55, J14, O41.

\section{Introduction}

In the next half a century an important demographic change to occur in large parts of the world is the increase in longevity. In the United States, for example, life expectancy at birth is currently equal to 77 and is expected to reach a level of approximately 83 in the year 2050 (United Nations, 2001). One of the most important causes of this spectacular rise in life expectancy is the higher rate of economic growth, as was emphasized by e.g. Fogel (1994). However, causality may also go in the other direction: an increase in longevity (or more generally, population ageing) can affect the rate of economic growth by boosting savings. Several studies have examined this, using the accumulation of physical capital as the engine of growth (e.g. Pecchenino and Pollard, 1997; Futugami and Nakajima, 2001). ${ }^{1}$

However, these studies do not account for the effect of demographic change on the aggregate consumption of different items, and therefore ignore the

\footnotetext{
${ }^{1}$ Other studies, such as Ehrlich and Lui (1991), Pecchenino and Utendorf (1999), and Zhang et al. (2001), focus on human capital as the engine of growth when analyzing the effects of ageing.

The analyses so far do not provide a clearly unambiguous effect of ageing on growth. This is in line with the results of empirical studies that either find a positive effect (Ehrlich and Lui, 1991: Barro and Sala-i-Martin, 1995) or a negative effect (Disney, 1996, ch.8; Lindh and Malmberg, 1999) of a larger old-age dependency ratio on economic growth.
} 
consequences that ageing will have on the economic structure. In an ageing society, the need for labour-intensive services will increase because elderly use more services, as was suggested by The Economist:

Older people... are likely to spend more on medical care and domestic services, such as those of gardeners and cleaners, that have risen sharply in price. Younger people are likely to spend more on new products, such as mobile phones or computers, which tend to fall rapidly in price during their early years.... In general many older people do indeed face higher inflation rates than the young.... Even if general inflation remains low, relative prices can shift significantly over as short a time as a decade, thanks to productivity gains brought by technological improvements, or to changes in demand; or, very often, both. (The price of age, The Economist, 21 December, 2000)

Budget surveys confirm this: the elderly spend 1.5 times as much of their total expenditures on services compared to younger households. ${ }^{2}$ Therefore, one can expect the production structure to change when the population is growing older. Because productivity improvements differ between the various sectors of the economy, a change in the relative size of these sectors is another channel through which overall economic growth will be affected.

In this paper, we focus on this mechanism by applying a model that combines the overlapping-generations structure of Diamond (1965) with the two-sector analysis of Baumol (1967) and endogenous growth due to learning by doing.

Following Baumol (1967), we group economic activities into two types: 'technologically progressive activities in which innovations, capital accumulation, and economies of large scale all make for a cumulative rise in output per man hour and activities which, by their very nature, permit only sporadic increases in productivity.' (Baumol, 1967, pp. 415-16). As to the first type of activity, 'labor is primarily an instrument', whereas the second type consists of 'services in which the labor is an end in itself, in which quality is judged directly in terms of amount of labor'. So we assume two sectors: a labour-intensive service sector and a capital-intensive commodity sector. Productivity growth is endogenously determined and mainly stems from technological progress that typically takes place in the commodity (or high-tech) sector.

As productivity grows, wages paid in this sector also increase. Because labour is assumed to be mobile between both sectors, the wage paid in the services sector will grow equally fast. The capital-intensive sector produces homogeneous consumption and investment commodities. These commodities are demanded by young individuals, whereas the elderly derive utility from labour-intensive services. Consequently, a change in the demographic composition of the economy will affect the relative aggregate demand for services and commodities.

\footnotetext{
${ }^{2}$ See ONS Family Spending 2000-01 for the United Kingdom and CBS Budgetonderzoek for The Netherlands.
} 
The structure of the economy, thereby the growth rate and the well-being of successive generations, are thus influenced.

Ageing is modeled as a permanently higher average lifetime. In a closed economy, which will be our benchmark case, the capital-labour ratio in the commodity sector will be influenced by domestic demographic changes. The longrun effects of ageing then crucially depend on the extent to which capital and labour are substitutable in the production process of commodities: if they are close substitutes, ageing will decrease growth, implying a continuously decreasing welfare for future generations, whereas the reverse holds if capital and labour are weak substitutes. In a small open economy, ageing leads to a lower long-run rate of economic growth because the increase in the relative number of elderly implies a lower domestic production of commodities.

The rest of this paper is organized as follows. Section 2 describes the model. In Section 3, we analyse the long-run consequences of population ageing in a closed economy. In Section 4, we discuss some extensions and modifications of the model. Section 5 concludes.

\section{The model}

Population ageing is a development with which many industrialized countries will be confronted. Because of the generality of this demographic trend, we take the closed economy as our benchmark case. ${ }^{3}$ We use a two overlapping-generations model. Following Baumol (1967), we distinguish between two sectors of production. In the commodity sector (labelled Y), homogeneous goods are produced that either serve as consumption or investment good. The service sector (labelled $D$ ) concerns the provision of labour-intensive services. In both sectors, firms are fully competitive and maximize profits. Labour is homogeneous and perfectly mobile across sectors, so the wage in both sectors is identical.

\subsection{Production of commodities}

Commodities are produced with physical capital and labour according to the following standard neoclassical CRTS production function: $Y_{t}=F\left(K_{t}, A_{t} L_{t}^{Y}\right)$, where $K_{t}$ stands for the domestic capital stock, $L_{t}^{Y}$ is the number of people employed in the commodity sector and $A_{t}$ is a productivity parameter reflecting the current state of (technological) knowledge or experience in the economy (all at time $t$ ). Production per effective unit of labour is described by $f\left(\kappa_{t}\right)$, with $\kappa_{t} \equiv\left(K_{t} / A_{t} L_{t}^{Y}\right)$ denoting the effective capital-labour ratio. The interest rate and wage are determined by the marginal productivity of capital and labour respectively, i.e. $r_{t}=f^{\prime}\left(\kappa_{t}\right)$ and $w_{t}=A_{t} \omega_{t}$, where $\omega_{t}=f\left(\kappa_{t}\right)-f^{\prime}\left(\kappa_{t}\right) \kappa_{t}$.

\footnotetext{
${ }^{3}$ Section 4.1 discusses the consequences of ageing for a small open economy where services are not internationally tradeable.
} 
Labour productivity grows at the endogenous rate $g$, which is assumed to depend positively on the number of people employed in the productive sector, ${ }^{4,5}$

$$
A_{t}=A_{t-1}\left(1+g\left(L_{t}^{Y}\right)\right)
$$

This can be interpreted as learning-by-doing, or as a shortcut for explicitly modeling (labour-intensive) R\&D activities or education. Alternatively, one could assume that part of the employees in the commodity sector devote their time to these activities, so the more people that are active in this sector of the economy, the more knowledge is created and skills are improved, which allows people to produce more final output, i.e. productivity increases (as in e.g. Romer, 1990; Grossman and Helpman, 1991; Mulligan and Sala-i-Martin, 1993).

\subsection{Production of services}

The production of services requires labour only and does not benefit from technological improvements. ${ }^{6}$ For the sake of simplicity, it is assumed that one unit of labour translates into one service. Consequently, total provision of services equals total labour supply in this sector $\left(L_{t}^{D}\right)$ and the price of services in terms of commodities, $p_{t}$, is equal to the wage: $p_{t}=w_{t}$.

\subsection{Households}

The economy is inhabited by a constant large number of individuals (normalized to 1) who live for at most two periods, such that in each period, both a young and an old generation are alive. ${ }^{7}$ Every young individual faces a probability of $\varepsilon$ to grow old, so $1-\varepsilon$ is the fraction of young that dies after one period of life and $\varepsilon$ can be interpreted as a measure for average longevity. Note that $\varepsilon$ also reflects the number of retired per young people, i.e. the old-age dependency ratio. When people grow old, the need for services increases, both because of increased disability (which raises the demand for e.g. care services and housekeeping assistance) and a higher preference for services relative to (high-tech) commodities.

\footnotetext{
${ }^{4}$ It may well be that the economy also adopts new technologies and increases its knowledge from abroad. In that case, the size of the commodity sector positively affects the additional productivity growth of the economy.

${ }^{5}$ Note that we assume $A$ to grow instantly with the size of the sector. If learning takes time, however, one would rather want to assume some delay in the accumulation of knowledge. However, assuming that $g$ is a function of $L_{t-1}^{Y}$ instead of $L_{t}^{Y}$ would imply that learning takes about 30 years (i.e. one period in our model), which does not seem to be very realistic.

${ }^{6}$ Examples are nurses, GPs, residential care, gardeners, cleaners, housekeepers, hairdressers, butlers, and hotel service staff. Note that these are not services like bank services which extensively use high-tech goods like computers.

${ }^{7}$ In Section 4.3 population growth is included in order to analyse the effects of ageing as a drop in fertility.
} 
To simplify the analysis, we will assume that old individuals demand services only, and young people merely consume commodities. The expected lifetime utility of a representative agent born at any time $t$ can then be represented by the following function,

$$
E_{t} U\left(c_{t}, d_{t+1}\right)=\log c_{t}+\gamma \varepsilon \log d_{t+1},
$$

where $c_{t}$ stands for the consumption of commodities when young and $d_{t+1}$ is the number of services enjoyed by the agent when old. ${ }^{8}$

This kind of utility function ensures that the number of services demanded, and thus the allocation of labour over the two sectors, is constant for a given growth rate of wages, i.e. a given growth rate of the relative price of services. This is necessary for an equilibrium to exist, and limits the class of utility functions that can be applied. The log-linear function used here is the most straightforward type of such a utility function. ${ }^{9}$

Every young individual supplies one unit of labour inelastically and participates in an actuarially fair pension fund..$^{10}$ Part of the wage he receives is taxed by the government at a (constant) rate $\tau$ to finance public pensions. Because this is a Pay-As-You-Go (PAYG) scheme, the benefit received when old is equal to $\left(\tau w_{t+1} / \varepsilon\right){ }^{11}$ The rest of first-period income is spent on consumption and pension savings $\left(s_{t}\right)$, which are collected by the pension fund and invested in annuities. ${ }^{12}$ As only a fraction $\varepsilon$ of young savers born at time $t$ survives to period $t+1$, the assets of those who deceased are passed on to surviving contemporaries. The return on the pension savings is therefore $\left(r_{t+1} / \varepsilon\right)$ per retired individual. Consumption possibilities are thus given by the following budget constraints,

$$
\begin{aligned}
c_{t} & =(1-\tau) w_{t}-s_{t}, \\
p_{t+1} d_{t+1} & =\frac{r_{t+1} s_{t}+\tau w_{t+1}}{\varepsilon} .
\end{aligned}
$$

\footnotetext{
${ }^{8}$ Allowing for consumption of services when young, or consumption of commodities when old does not qualitatively affect the results of higher longevity as long as the economy is dynamically efficient, i.e. $r>1+g\left(L^{Y}\right)$. However, the results can change if ageing is the result of a lower fertility rate (see Section 4.3).

${ }^{9}$ This is similar to the modeling of the labour/leisure choice in a model with economic growth. King $e t$ al. (1988) and Rebelo (1991) formulate the class of utility functions for which the number of leisure hours does not grow indefinitely (see also Barro and Sala-i-Martin, 1995, ch. 9).

${ }^{10}$ In many European countries, savings for old age are organized collectively via pension funds. These funds typically provide insurance against demographic risks at low costs. So savings in our model can be interpreted as savings via pension funds.

${ }^{11}$ Because the social security tax is assumed to the constant, the public benefit will change due to ageing. Instead, we could assume the benefit to be constant and taxes to vary. Section 4.2 deals with this case.

${ }^{12}$ Alternatively, one could assume that part of savings is not invested in annuities, leading to unintentional bequests. This weakens the effects of ageing, but the results do not differ qualitatively.
} 
Maximizing (2) subject to (3a) and (3b) results in the following demand and saving functions,

$$
\begin{aligned}
c_{t} & =\frac{1}{1+\gamma \varepsilon}\left((1-\tau) w_{t}+\frac{\tau w_{t+1}}{r_{t+1}}\right), \\
d_{t+1} & =\frac{\gamma r_{t+1}}{w_{t+1}(1+\gamma \varepsilon)}\left((1-\tau) w_{t}+\frac{\tau w_{t+1}}{r_{t+1}}\right), \\
s_{t} & =\frac{\gamma \varepsilon(1-\tau) w_{t}}{1+\gamma \varepsilon}-\frac{\tau w_{t+1}}{(1+\gamma \varepsilon) r_{t+1}} .
\end{aligned}
$$

So a fixed share of lifetime income in terms of commodities (which is given by $\left.(1-\tau) w_{t}+\left(\tau w_{t+1} / r_{t+1}\right)\right)$ is allocated to commodities and services. Note that $\left(w_{t+1} / r_{t+1}\right)$ is the relative price of services during old age in terms of current commodities.

As $w_{t}=A_{t} \omega_{t}$, lifetime income grows over time with the rate of technological progress. According to (4), this will also be the case for the consumption of commodities. The relative price of services will grow at a constant rate as well. This causes a negative substitution effect on the number of services demanded, which exactly offsets the positive income effect, so that the number of services enjoyed is constant for a given growth rate.

\subsection{Equilibrium}

The model comprises four markets that are simultaneously in equilibrium at each point in time. Total demand for services by the old has to be met by labour supply of the young to this sector, so $L_{t}^{D}=\varepsilon d_{t}$. Labour market clearing implies that $L_{t}^{Y}=1-L_{t}^{D}$. These equilibrium conditions in combination with the individual first-order conditions lead to the following expression for the employment share of the commodity sector,

$$
\begin{aligned}
L_{t}^{Y} & =1-\frac{r_{t} s_{t-1}+\tau w_{t}}{p_{t}} \\
& =1-\frac{\gamma \varepsilon(1-\tau) r_{t} \omega_{t-1}}{(1+\gamma \varepsilon)\left(1+g\left(L_{t}^{Y}\right)\right) \omega_{t}}-\frac{\gamma \varepsilon \tau}{1+\gamma \varepsilon} .
\end{aligned}
$$

In a closed economy, the demand for commodities, which consists of consumption and investment $\left(K_{t+1}\right),{ }^{13}$ must equal aggregate domestic production, so $Y_{t}=c_{t}+K_{t+1}$. The capital market clears if $s_{t}=K_{t+1}$.

\footnotetext{
${ }^{13}$ Capital is assumed to fully depreciate in one period.
} 


\section{Ageing in a closed economy}

The long-run impact of population ageing on the rate of economic growth depends on the extent to which capital and labour can be substituted in the production process of commodities, as stated in the following proposition.

Proposition 1 In a closed economy, higher longevity results in slower (faster) growth if the elasticity of substitution between capital and labour is greater (smaller) than unity. Ageing has no effect on growth if this elasticity equals unity. The capital-labour ratio increases.

Proof All proofs are given in the Appendix.

Higher longevity encourages people to save more when young so that the capital stock that is used in the commodity sector rises, stimulating labour to move from the services sector to the commodity sector. This effect will be particularly strong if capital and labour are weak substitutes. On the other hand, the total demand for services increases, since more people will be retired, which incites labour to move in the opposite direction, away from the commodity sector. If capital and labour are close substitutes in the commodity sector, this last effect will be dominant and $L^{Y}$ decreases; the reverse holds in case of weak substitutability. With a Cobb-Douglas production function, capital and labour are neither close nor weak substitutes, so ageing causes no change in the division of labour and thereby in the growth rate. ${ }^{14}$

\subsection{Exogenous vs. endogenous growth}

The effects of a longer life span on the utility of subsequent generations in a closed economy are displayed in Fig. 1, in case there is constant exogenous growth $\left(g^{\prime}=0\right)$ and in case growth is endogenous $\left(g^{\prime}>0\right)$. The life span increases unexpectedly at time $t=0$. The elderly living at the time of the shock did not foresee this demographic shock when they were young. The current and future young individuals, however, take this change and its general-equilibrium effects into account in their consumption and savings decisions. ${ }^{15}$

\footnotetext{
${ }^{14}$ This directly follows from the equilibrium condition for the commodity market, according to which the wage share does not depend on the capital-labour ratio. That is, if the production elasticity of capital is $a$, then $\left(w_{t} A_{t} L_{t}^{Y}\right) / Y_{t}=1-a$, so that $L_{t}^{Y}=1-a$. Allowing for consumption of services by the young does not change this result.

${ }^{15}$ All simulations are based on the assumption that productivity growth is a linear function of the number of employees in the productive section, i.e. $g_{t}=\bar{g}+\rho L_{t}^{Y}$, where $\bar{g}$ has such a value that the equilibrium growth rate, both in case of exogenous and endogenous growth, is equals to 1 (which corresponds to an annual economywide growth rate of about $2.3 \%$ ). The cases considered are $\rho \rightarrow 0$ and $\rho=1.5$ respectively. The production function of commodities is given by $Y_{t}=\left(0.3 K_{t}^{\psi}+0.7\left(A_{t} L_{t}^{Y}\right)^{\psi}\right)^{1 / \psi}$. Furthermore, $\gamma=0.75, \tau=0.15$ and $\varepsilon$ increases from $2 / 3$ to 0.7 . If capital and labour are weak substitutes, the elasticity of substitution $(\sigma \equiv(1 /(1-\psi)))$ is set equal to 0.8 , and in case of close substitutability, a value of 1.1 is taken. When comparing the utility before and after ageing, we calculate the utility of individuals who live both periods before and after the shock.
} 


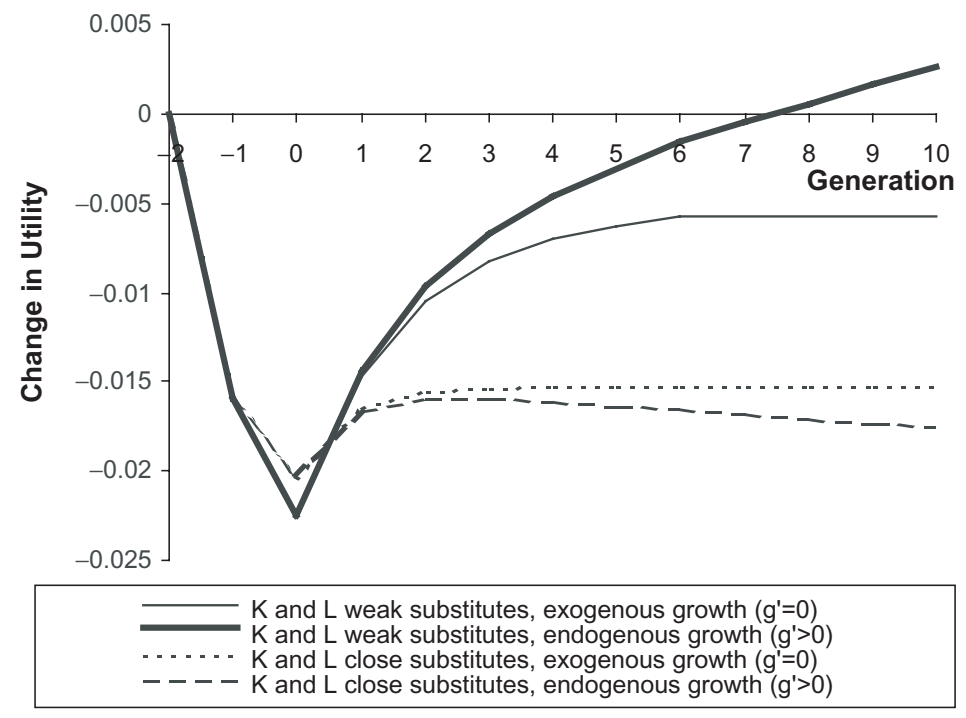

Fig. 1. Effect of higher longevity on lifetime utility in a closed economy

Higher longevity does not influence the allocation of labour over the two sectors in the short run. The generation of elderly at time $t=0$ cannot react to the fact that more contemporaries survive, so that the initial capital stock is given. The generation of young in this period can and will react by increasing savings. As this is merely a shift from consumption to investment that does not affect total demand for commodities, this will not change the allocation of labour over the two sectors and the capital-labour ratio in the commodity sector is not influenced either. Consequently, economic growth and factor rewards will initially not be affected. The group of retired at $t=0$ as a whole therefore receives the same return on savings, but since more people survived, each elderly individual gets a lower return on his pension savings. Furthermore, the rise in the old-age dependency ratio implies a lower PAYG-benefit, which also has a detrimental effect on the utility of the initially retired.

The generation of young people at time $t=0$ receives the same wage as before, but will decide to save a higher fraction of it and consume fewer commodities. These higher savings translate into a higher capital-labour ratio in the next period. Consequently, wages rise and services become more expensive at time $t=1$. This higher wage has a negative effect on the utility of the generation born at $t=0$, which is added to the negative utility effect of the decreased individual return on their savings due to ageing.

The generation born at time $t=1$ earns a higher wage when young, so this cohort receives a partial compensation for the negative utility effect of ageing on their returns on savings.

Note that wages rise more strongly if capital and labour are weak substitutes in the production process of commodities than in the case where they are close 
substitutes. If growth is exogenous, the wage will stabilize at a higher level, but this effect is not strong enough to outweigh the negative effect on utility of a lower interest rate and public pension benefit. Utility will converge to a permanently lower level. However, if productivity growth is brought about endogenously, the wage growth is positively influenced by ageing if the factors of production are weak substitutes. Eventually, this positive growth effect will dominate and utility will be at a continuously higher level than before. In case labour and capital are close substitutes, the endogenous wage growth will decrease, which adds to the negative effect on utility of a lower interest rate and PAYG-pension benefit, leading to a continuously lower level of well-being.

\section{Extensions and modifications}

In this section we explore the effects of population ageing when the basic model presented above is extended or modified in several ways. ${ }^{16}$ First, we analyse the consequences of ageing if the economy is a small open economy with perfect capital mobility. Subsequently, we study what changes if the government promises a public benefit that is indexed to the price of services. In Section 4.3, we consider the consequences of ageing if this is caused by a lower rate of population growth. Section 4.4 focuses on the externality due to learning-by-doing in the commodity sector which implies that the consumption of services will be too high since individuals do not take account of the fact that consumption of commodities stimulates employment in this sector and thus economic growth. We analyse how the allocation chosen by a social planner (who internalizes the externality) changes in case of an ageing society. Finally, we study how robust the results are if we replace the assumption that growth is due to learning-by-doing in the commodity sector by the assumption that technological development is directly linked to the use of capital.

\subsection{Ageing in a small open economy}

As the timing and/or rate of demographic change differs between some countries, it is also of interest to consider ageing in a multi-country world. A natural extension of the closed-economy model of the previous section is a model of a small open economy with perfect capital mobility. The results of intermediate cases, like a two-country model with equally large populations, can then be derived by combining the closed-economy and the small-open-economy case.

For the small open economy the effects of a change in longevity can be traced by differentiating (8) with $r_{t}=r$ and $\omega_{t}=\omega$, and evaluating the result in the initial steady state. This leads to the following proposition.

Proposition 2 In a small open economy, higher longevity reduces economic growth.

\footnotetext{
${ }^{16}$ The Appendix contains a more detailed analysis of these extensions and modifications.
} 
If people expect to live longer, they will decide to save more when they are young. With the return on these additional savings, the retired generation consumes more services. Because of that, the number of young people employed in that sector increases, leaving fewer people in the capital-intensive commodity sector. As a consequence, the growth rate decreases. A lower growth rate implies that future services become cheaper. As can be seen from (5), this implies that each retired person will use more services.

4.1.1 Exogenous vs. endogenous growth Figure 2 shows the consequences of population ageing on the lifetime utility of successive generations. The life span increases unexpectedly at time $t=0$, and the economy will be in its new steady state as from $t=1 \mathrm{on}$. The old living at the time of the shock did not foresee this shock when they made their savings decision. Therefore, the spending on services for this generation as a whole remains unchanged. Consequently, the allocation of labour over the two sectors does not change either, and growth is initially not affected by ageing (as in a closed economy).

In the case without endogenous productivity changes $\left(g^{\prime}=0\right)$ factor rewards do not change, and the real interest rate remains unaffected as a result. However, as more people reach old age, a smaller amount of assets is passed on from the deceased to surviving contemporaries, so the individual return on savings falls. Furthermore, the public PAYG-benefit decreases due to a rising old-age dependency ratio. The decrease in utility that results from this is larger for the generation that is old at the time of the shock than for the subsequent generations because, in contrast to the current elderly, these subsequent generations can partly compensate for the lower return by increasing savings.

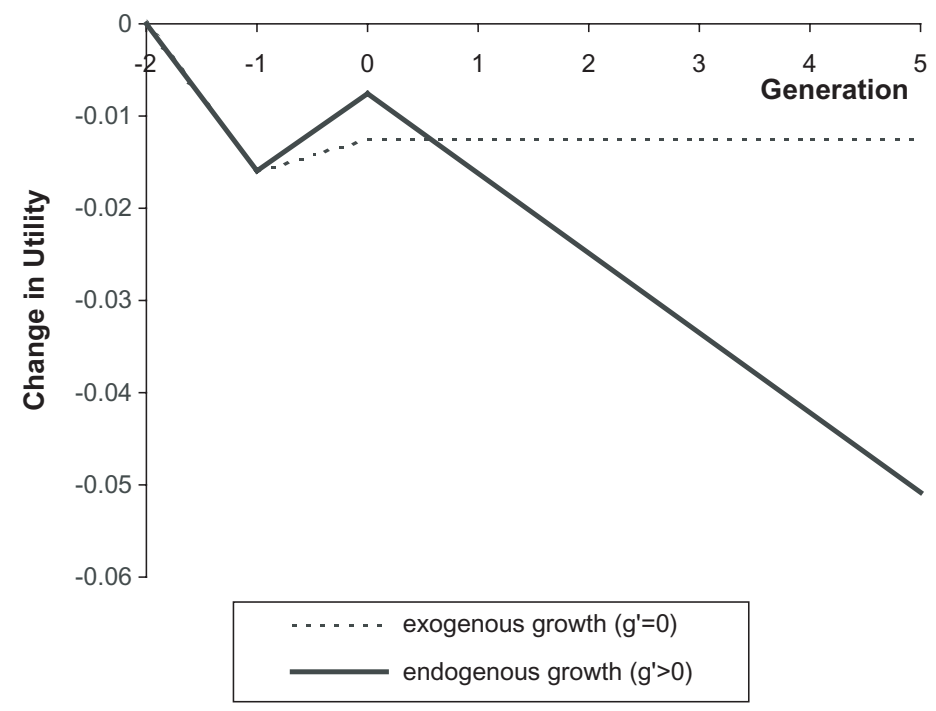

Fig. 2. Effect of higher longevity on lifetime utility in a small open economy 
With endogenous growth $\left(g^{\prime}>0\right)$, the effects for the currently old are not different from the case in which $g^{\prime}=0$ because the number of employees in the commodity sector does not change at the time of the shock. The wage of the individuals born at time $t=0$ therefore does not change either. However, at time $t=1$, wage growth will be lower. Consequently, the services that the generation born at the time of the shock will buy when they are old will be cheaper. This positive price effect alleviates the negative effect of a longer life span on utility, which is why the utility of this generation decreases less if $g^{\prime}>0$ compared to the case without endogenous growth. In the long run, individuals unambiguously suffer from the fact that ageing reduces productivity growth. This is a typical example of the 'Dutch disease': increased savings lead to a higher import of commodities and the country specializes more in the production of non-tradeable, low-tech services, which lowers productivity growth. Note that the reverse holds if other countries have a relatively more ageing society (e.g. Japan compared to the United States). In that case, the younger country will experience a capital inflow from abroad which stimulates productivity growth.

\subsection{Fixed PAYG-pension benefits}

In case the social security benefit is indexed to the price of services so that the benefit always equals $\eta p_{t}$, the PAYG-tax is flexible and responds to changes in the demographic structure: $\tau_{t}=\eta \varepsilon$. That is, ageing automatically raises the consumption of services by the old, and there will be less need to raise savings. As in the benchmark model, the effect on growth of higher service consumption depends on the substitutability of labour and capital. The long-run effects of ageing, therefore, do not change qualitatively. In the short run, however, a higher number of elderly people will spend their social security benefits on services, so fewer people will be employed in the commodity sector and growth decreases.

\subsection{Population ageing as a lower fertility rate}

Suppose the economy is inhabited by $N_{t}$ young people at time $t$, and population grows at rate $n$, such that $N_{t+1}=\left(1+n_{t+1}\right) N_{t}$. Ageing takes the form of a lower value of $n$, and equilibrium in the labour market implies that $N_{t}=L_{t}^{Y}+L_{t}^{D}$. We now assume that the productivity growth rate depends on the fraction of young people employed in the productive sector: $g_{t}=g\left(l_{t}^{Y}\right)$, with $l_{t}^{Y} \equiv\left(L_{t}^{Y} / N_{t}\right)$. Furthermore, we take $\varepsilon$ equal to unity.

In a closed economy, the long-run effects of a lower rate of fertility are the same as those of a longer lifespan. In both cases, the capital-labour ratio rises and the wage increases. However, the underlying mechanism is different. A longer life span directly implies a stronger incentive to save, which is absent if fertility decreases. In the latter case, the number of workers $\left(N_{t}\right)$ decreases, which immediately causes a rise in the capital-labour ratio. Furthermore, both 
types of population ageing lead to a higher old-age dependency ratio, implying a lower PAYG-pension benefit and a stronger incentive to save. Whether the (relative) number of employees in the commodity sector will decrease again depends on the substitutability of capital and labour in the commodity sector: if they are weak substitutes, the attachment of labour to the commodity sector will be dominant, whereas in case of close substitutes, labour will be released to the service sector.

Notice that contrary to higher longevity, a lower population growth rate does affect productivity growth in the short run. This is so because a lower fertility rate immediately decreases the number of young individuals, whereas the capital stock is fixed in the short run. In our benchmark case where longevity increases, the capital-labour ratio is affected for the first time one period after the shock, when higher savings of the previous young generation are embodied in a larger capital stock.

\subsection{A social planner}

In the model presented above, productivity growth results from learning-bydoing spillovers in the commodity sector. This implies that the production of goods involves a positive externality, which individuals do not take into account when they make their consumption choices. So if there was a social planner, whose objective function consists of the lifetime utilities of all current and future generations, these spillover effects would be internalized by choosing a smaller number of services and a larger consumption of commodities than individuals would choose. Since the structure of the model does not essentially change by assuming a social planner, the consequences of ageing will not be qualitatively different. There will be quantitative differences, however. If ageing leads to a higher consumption of services, so that growth decreases, this will be less so in case the social planner decides. If ageing leads to higher growth, a social planner will internalize the positive spillover effect, and growth will increase more. Hence, the effects on growth will be less negative or more positive. ${ }^{17}$

\subsection{Capital-induced growth}

Suppose the development of labour productivity in the commodity sector not only depends on the number of people employed in that sector, but also on the capital-labour ratio. In a closed economy, the capital-labour ratio increases due to ageing. This by itself would stimulate productivity growth, and can offset the negative effect on growth of a smaller number of workers in the commodity sector if capital and labour are close substitutes. So ageing will lead to an increase in long-run growth for a larger range of values of the elasticity of substitution

${ }^{17} \mathrm{~A}$ more detailed analysis of this extension is available upon request. 
between capital and labour than in the case where growth does not depend on the capital stock. It is therefore more likely that population ageing increases economic growth in the long run if productivity growth also depends on the size of the capital stock.

\section{Conclusions}

In this paper, we analysed the effect of population ageing on growth, by pointing at two mechanisms, one of which received little attention so far. The first mechanism is the standard result that ageing will increase the accumulation of capital and thereby stimulate growth. The second mechanism, however, causes an opposite effect. Due to a shift in demand towards more labour-intensive services, the structure of the economy will change and accordingly, productivity growth will slow down. In a closed economy, the ultimate effect depends on the elasticity of substitution between the production factors in the productive sector. In a small open economy, the first effect does not occur, so growth will decrease due to ageing in such an economy. It was demonstrated that the results we found do not change significantly if the model is modified or extended in several ways.

This paper offers several interesting directions for further research. In order to analyse the quantitative effects, the framework applied can be incorporated in more extensive simulation models which are used for policy analysis. Further extensions can be found by combining the ideas of this paper with existing growth theories that explicitly include for instance $\mathrm{R} \& \mathrm{D}$-expenditures as the source of economic growth or human capital accumulation. Another extension would be to allow for a richer definition of technological progress, one that also takes account of demand-driven advances in the medical service sector. In this way, we can achieve a better understanding of the effects of demographic changes on the economy, which is necessary for formulating appropriate policies as an adequate device to battle the ageing problem.

\section{References}

Barro, R.J. and Sala-i-Martin, X. (1995) Economic Growth, McGraw-Hill, New York.

Baumol, W.J. (1967) Macroeconomics of unbalanced growth: the anatomy of urban crisis, American Economic Review, 57, 415-26.

Diamond, P.A. (1965) National debt in a neoclassical growth model, American Economic Review, 55, 1126-50.

Disney, R. (1996) Can We Afford to Grow Older? MIT Press, Cambridge, MA.

Ehrlich, I. and Lui, F.T. (1991) Intergenerational trade, longevity, and economic growth, Journal of Political Economy, 99, 1029-59.

Fogel, R.W. (1994) Economic growth, population theory, and physiology: the bearing of long-term processes on the making of economic policy, American Economic Review, 84, 369-95. 
Futagami, K. and Nakajima, T. (2001) Population ageing and economic growth, Journal of Macroeconomics, 23, 31-44.

Grossman, G.M. and Helpman, E. (1991) Innovation and Growth in the Global Economy, MIT Press, Cambridge, MA.

King, R.G., Plosser, C.I., and Rebelo, S. (1988) Production, growth and business cycles: I. The basic neoclassical model, Journal of Monetary Economics, 21, 195-232.

Lindh, T. and Malmberg, B. (1999) Age structure effects and growth in the OECD, 1950-1990, Journal of Population Economics, 12, 431-50.

Mulligan, C.S. and Sala-i-Martin, X. (1993) Transitional dynamics in two-sector models of endogenous growth, Quarterly Journal of Economics, 108, 737-73.

Pecchenino, R.A. and Pollard, P.S. (1997) The effects of annuities, bequests, and aging in an overlapping generations model of endogenous growth, Economic Journal, 107, 26-46.

Pecchenino, R.A. and Utendorf, K.R. (1999) Social security, social welfare and the ageing population, Journal of Population Economics, 12, 607-23.

Rebelo, S. (1991) Long-run policy analysis and long-run growth, Journal of Political Economy, 99, 500-21.

Romer, P.M. (1990) Endogenous technological change, Journal of Political Economy, 98, S71-S102.

United Nations (2001) World Population Prospects: The 2000 Revision, United Nations, New York.

Zhang, J., Zhang, J., and Lee, R. (2001) Mortality decline and long-run growth, Journal of Public Economics, 80, 485-507.

\section{Appendix}

Throughout the paper, three assumptions are made.

Assumption 1 A steady state exists, i.e. the function $g(x)$ is such that $\exists x \in(0,1) \mid$ $1-(r \gamma \varepsilon(1-\tau) /((1+\gamma \varepsilon)(1+g(x)))-(\gamma \varepsilon \tau /(1+\gamma \varepsilon))=x$.

Assumption 2 The economy converges to the steady state.

Assumption 3 Endogenous growth effects are bounded, such that in steady state $g^{\prime}<\left((1+\gamma \varepsilon)\left(1+g\left(L_{t}^{Y}\right)\right)^{2} /(r \gamma \varepsilon(1-\tau))\right)-\forall L_{t}^{Y}$.

\section{Appendix to Section 3}

In a closed economy, it follows from (3a) and equilibrium in the commodity market that

$$
L_{t}^{Y}=(1-\tau)\left(1-\frac{\kappa_{t} f^{\prime}\left(\kappa_{t}\right)}{f\left(\kappa_{t}\right)}\right)
$$

and from the equilibrium condition of the capital market that

$$
\frac{s_{t}}{A_{t}\left(1+g\left(L_{t+1}^{Y}\right)\right)}=\kappa_{t+1} L_{t+1}^{Y}
$$


Linearizing eq. (A1) at time $t+1$ yields

$$
d L_{t+1}^{Y}=\delta d \kappa_{t+1}
$$

with $\delta \equiv\left((1-\tau)(\sigma-1) \kappa f^{\prime \prime}(\kappa)\right) / f(\kappa)$, and $\sigma$ denoting the elasticity of substitution between capital and labour, i.e. $\sigma \equiv-\left(f^{\prime}\left(\kappa_{t}\right) \omega_{t}\right) /\left(f\left(\kappa_{t}\right) \kappa_{t} f^{\prime \prime}\left(\kappa_{t}\right)\right)$.

Linearizing (8) at time $t+1$ gives

$$
d L_{t+1}^{Y}=\lambda_{1} d \kappa_{t}+\lambda_{2} d \kappa_{t+1}+\lambda_{3} d \varepsilon
$$

where $\left.\quad \lambda_{1} \equiv\left((1+g) \gamma \varepsilon(1-\tau) r \kappa f^{\prime \prime}(\kappa)\right) /\left(\left((1+\gamma \varepsilon)(1+g)^{2}-\gamma \varepsilon(1-\tau) r g^{\prime}\right)(f(\kappa)-\kappa r)\right)\right)$, $\lambda_{2} \equiv-\lambda_{1}(f(\kappa) /(\kappa r)), \quad$ and $\quad \lambda_{3} \equiv-(\gamma(1+g)(r(1-\tau)+\tau(1+g))) /\left(\left((1+\gamma \varepsilon)(1+g)^{2}-\right.\right.$ $\left.\left.\gamma \varepsilon(1-\tau) r g^{\prime}\right)(1+\gamma \varepsilon)\right)$. Combining these two equations results in the following first-order difference equation,

$$
d L_{t+1}^{Y}=\frac{\lambda_{1}}{\delta-\lambda_{2}} d L_{t}^{Y}+\frac{\delta \lambda_{3}}{\delta-\lambda_{2}} d \varepsilon
$$

This difference equation is stable if $\left|\left(\lambda_{1} /\left(\delta-\lambda_{2}\right)\right)\right|<1$. Using (A2) it can be shown that $\delta-\lambda_{2}<0$. This implies that the stability condition boils down to $\delta-\lambda_{1}-\lambda_{2}<0$. In line with Assumption 2, we assume this condition to hold. Note that this is not a strong assumption. In fact, it can easily be shown that it follows from Assumption 3 if $\sigma \geq 1$. Furthermore, simulations with a linear growth function $\left(g_{t}=\bar{g}+\rho L_{t}^{Y}\right)$ show that the stability condition also holds for all values of $\sigma$ below unity for which a steady-state equilibrium exists.

1.1 Proof of Proposition 1 Setting $d L_{t+1}^{Y}=d L_{t}^{Y}=d L^{Y}$ in (A5) gives

$$
\frac{d L^{Y}}{d \varepsilon}=\frac{\delta \lambda_{3}}{\delta-\lambda_{1}-\lambda_{2}}
$$

Knowing that $\lambda_{3}<0$ and $\delta-\lambda_{1}-\lambda_{2}<0$ (stability), it follows that $\left(d L^{Y} / d \varepsilon\right) \lessgtr 0$ if $\sigma \leq 1$. Furthermore, eq. (A3) together with (A6) shows that $(d \kappa / d \varepsilon)>0$ if $\sigma \neq 1$. If $\sigma=1$, then $\delta=0 \quad$ so $\quad\left(d L^{Y} / d \varepsilon\right)=0 \quad$ and $\quad(d \kappa / d \varepsilon)=-(r(1-\tau)+\tau(1+g)) /$ $\left((1+\gamma \varepsilon)(f(\kappa)-\kappa r) \varepsilon f^{\prime \prime}(\kappa)(1-\tau)\right)>0$.

1.2 Short-run effect Differentiating (A1) at time $t=0$ gives $\left(d L_{0}^{Y} / d \varepsilon\right)=\delta\left(d \kappa_{0} / d \varepsilon\right)$. Furthermore, differentiating the capital market eq. (A2) at time $t=0$, taking savings of the previous period as given, results in $\left(d \kappa_{0} / d \varepsilon\right)=-\kappa\left(\left(g^{\prime} /(1+g)\right)+\left(1 / L^{Y}\right)\right)\left(d L_{0}^{Y} / d \varepsilon\right)$. Combining these two expressions gives $\left(d \kappa_{0} / d \varepsilon\right)=\left(d L_{0}^{Y} / d \varepsilon\right)=0$.

\section{Appendix to Section 4}

2.1 A small open economy Comparative statics of (8) with $r_{t}=r$ and $\omega_{t}=\omega$ yields

$$
\frac{d L^{Y}}{d \varepsilon}=\frac{\gamma(1+g)(r(1-\tau)+\tau(1+g))}{(1+\gamma \varepsilon)\left((1+\gamma \varepsilon)(1+g)^{2}-\gamma \varepsilon r(1-\tau) g^{\prime}\right)}<0 .
$$


Assumption 3 implies that the denominator of (A7) is positive, so $\left(d L^{Y} / d \varepsilon\right)<0$.

2.2 Population ageing as a lower fertility rate The PAYG-benefit that an old individual at time $t+1$ receives now equals $\left(1+n_{t+1}\right) \tau w_{t+1}$. Assumption 3 changes to $g^{\prime}<\left((1+\gamma)\left(1+g\left(l_{t}^{Y}\right)\right)^{2}(1+n)\right) /(r \gamma(1-\tau))$.

In a closed economy, lower fertility decreases (increases) growth initially as well as in the long run if the elasticity of substitution between capital and labour is greater (smaller) than unity. Ageing has no effect on initial and long-run growth if this elasticity equals unity. The proof of the long run results is analogous to that of Proposition 1. The initial effect follows from differentiating the equilibrium condition for the commodity market (eq. (A1) with $l^{y}$ instead of $\left.L^{y}\right)$ at time $t=0$ which gives $\left(d l_{0}^{Y} / d n_{0}\right)=\delta\left(d \kappa_{0} / d n_{0}\right)$. Furthermore, equilibrium in the capital market is now given by $s_{t} /\left(A_{t}\left(1+g\left(l_{t+1}^{Y}\right)\right)\right)=$ $\kappa_{t+1} l_{t+1}^{Y}\left(1+n_{t+1}\right)$. Taking savings as given, differentiating this equation results in

$$
\frac{d \kappa_{0}}{d n_{0}}=-\kappa\left(\frac{g^{\prime}}{1+g}+\frac{1}{l^{Y}}\right) \frac{d l_{0}^{Y}}{d n_{0}}-\frac{\kappa}{1+n} .
$$

Combining these two expressions and rewriting gives

$$
\frac{d l_{0}^{Y}}{d n}\left(1+\delta \kappa\left(\frac{g^{\prime}}{1+g}+\frac{1}{l^{Y}}\right)\right)=-\frac{\delta \kappa}{1+n} .
$$

The RHS of this expression is positive (negative) if $\sigma>(<) 1$, whereas the LHS can numerically be shown to be positive. Hence, $\left(d l_{0}^{Y} / d n\right)>0$ if $\sigma>1$, and the opposite holds if $\sigma<1$. From this it immediately follows that $\left(d \kappa_{0} / d n\right)<0$. In case of a Cobb-Douglas production function $(\sigma=1),\left(d l_{0}^{Y} / d n\right)=0$ and $\left(d \kappa_{0} / d n\right)=-\kappa /(1+n)<0$.

2.3 Capital-induced growth Suppose the development of labour productivity in the commodity sector not only depends on the number of employed people, but also on the capital stock they use, according to the following function,

$$
A_{t}=A_{t-1}\left(1+g\left(L_{t}^{Y}, \kappa_{t}\right)\right)
$$

Eq. (8), describing equilibrium in the labour and services market, now changes to

$$
L_{t}^{Y}=1-\frac{\gamma \varepsilon(1-\tau) r_{t}}{(1+\gamma \varepsilon)\left(1+g\left(L_{t}^{Y}, \kappa_{t}\right)\right)}-\frac{\gamma \varepsilon \tau}{1+\gamma \varepsilon}
$$

Linearizing this equation gives

$$
d L_{t+1}^{Y}=\lambda_{1} d \kappa_{t}+\hat{\lambda}_{2} d \kappa_{t+1}+\lambda_{3} d \varepsilon
$$

with $\hat{\lambda}_{2} \equiv \lambda_{2}+\lambda_{1}\left(\left(g_{k} \omega\right) /\left(\kappa f^{\prime \prime}(\kappa)(1+g)\right)\right)$. Notice that $\hat{\lambda}_{2}>\lambda_{2}$, so the change in the number of individuals employed in the commodity sector, which is now given by

$$
\frac{d L^{Y}}{d \varepsilon}=\frac{\delta \lambda_{3}}{\delta-\lambda_{1}-\hat{\lambda}_{2}},
$$


is (in absolute terms) smaller than before.

The change in the growth rate due to ageing is

$$
\frac{d g}{d \varepsilon}=\left(\delta g_{L}+g_{\kappa}\right) \frac{\lambda_{3}}{\delta-\lambda_{1}-\hat{\lambda}_{2}}
$$

with $g_{L} \equiv\left(\partial g / \partial L^{Y}\right)$. This expression is negative if $\delta g_{L}+g_{\kappa}<0 \Longleftrightarrow$ $\sigma>1-\left(g_{\kappa} / g_{L}\right)\left(f(\kappa) /\left(\kappa f^{\prime \prime}(\kappa)\right)\right)>1$. 